\title{
ANALISIS STRUKTUR MIKRO PADA PADA NOVEL AYAT-AYAT CINTA 2 KARYA HABIBURRAHMAN EL SHIRAZY : KAJIAN ANALISIS WACANA KRITIS VAN DIJK
}

\author{
Wahyu Ningsih ${ }^{1}$, T. Silvana Sinar ${ }^{2}$, T. Thyrhaya Zein $^{3}$ \\ E-mail: ${ }^{1}$ wahyuningsih@unprimdn.ac.id, ${ }^{2}$ tengkusilvana@usu.ac.id, \\ 3 t.thyrhaya@usu.ac.id \\ Linguistik, Fakultas Ilmu Budaya, Universitas Sumatera Utara, Indonesia
}

\begin{abstract}
ABSTRAK
Habiburahman El Shirazy memberikan gambaran atas situasi sosial yang mempresentasikan ideologi kebudayaan bangsa dan agamanya melalui sebuah novel. Adapun penelitian ini bertujuan untuk struktur mikro yang terdapat pada novel Ayat-Ayat Cinta 2 karya Habiburahman El Shirazy. Penelitian ini menggunakan teori Analisis Wacana Kritis van Dijk. Jenis penelitian ini termasuk ke dalam jenis penelitian analisis isi. Data pada penelitian ini adalah novel Ayat-Ayat Cinta 2 karya Habiburahman El Shirazy. Teknik pengumpulan data dilakukan dengan cara mencatat dokumen. Setelah data terkumpul, kemudian data dianalisis dengan menggunakan model interaktif Miles, Hubberman dan Saldana. Berdasarkan hasil penelitian diketahui bahwa pada level struktur mikro, Habiburahman El Shirazy, menyelipkan ideologi melalui pilihanpilihan kata untuk menyampaikan pesan-pesan Islami.
\end{abstract}

Kata Kunci : Ayat-Ayat Cinta 2, Struktur Mikro. Analisis Wacana Kritis

\section{PENDAHULUAN}

Novel merupakan hasil karya sastra yang di dalamnya mengungkapkan masalah-masalah yang terdapat dalam kehidupan, baik yang berkaitan dengan nilai-nilai sosial, filsafat, moral, religius, maupun hal-hal yang ada di dalam kehidupan, sehingga dapat disimpulkan bahwa novel merupakan satu bentuk cerita rekaan yang kompleks dan bermakna (Sugihastuti dan Suharto, 2002: 43).

Banyak orang beranggapan bahwa tokoh utama pada sebuah novel merupakan tokoh yang sama dengan pengarangnya, apalagi jika tokoh tersebut memiliki jenis kelamin yang sama dengan pengarangnya (Kusmayadi, 2008: 12). Sebagai pengarang novel, terdapat ideologi yang mengalir dalam karyanya.

Habiburrahman El Shirazy (Selanjutnya disingkat HES) merupakan seorang novelis nomor 1 di Indonesia. Melalui karya-karyanya, HES seolah-olah mengarahkan atau memberikan pandangan keberadaan sekitarnya melalui ideologi yang digunakan pada novelnya. Selain novelis, HES juga dikenal sebagai 
sutradara, dai, penyair, sastrawan, pimpinan pesantren, dan penceramah. HES banyak menulis novel tentang keteladanan tokoh dan hal-hal positif yang mengajarkan tentang kebaikan. Secara umum melalui tokoh-tokoh yang berperan dalam novel -novel karya HES terdiri atas tokoh laki-laki dan perempuan selalu ditampilkan dengan berbagai permasalahan, peran, fungsi, serta citranya mengarahkan pembaca pada pengimajian yang dibuat oleh pengarang yang dapat diungkapkan melalui citra yang menyerupai gambaran yang dihasilkan oleh hasil tafsiran pembaca terhadap suatu objek.

Pemilihan novel karya HES sebagai subjek penelitian dilatarbelakangi oleh adanya keinginan peneliti untuk menemukan ideologi yang terkandung pada novel tersebut dan apa yang melatarbelakangi HES menulis novel tersebut. HES juga menanamkan banyak pesan dalam setiap novelnya yaitu bagaimana seorang muslim harus menjadi muslim yang memiliki aqidah yang teguh dan toleran terhadap agama lain.

Pada novel-novelnya, HES memberikan gambaran atas situasi sosial yang mempresentasikan ideologi kebudayaan bangsa dan agamanya. Ideologi pada sebuah novel dapat ditransfer melalui dialog tokoh, latar, peristiwa, maupun karakter tokoh. Melalui hal-hal tersebut, HES seolah-olah mengarahkan atau memberikan pandangan keberadaan sekitarnya melalui ideologi yang digunakan, dan ideologi tersebut memang berkaitan merujuk kepada agama dan religi, keyakinan, nilai-nilai dan konsep ideal mengenai pemahaman Islam

Menurut van Dijk (1993) “ideologi melambangkan prinsip-prinsip yang mendasari kognisi sosial dan karenanya membentuk dasar-dasar pengetahuan, sikap, dan lebih spesifik lagi kepercayaan-kepercayaan yang digunakan bersama oleh suatu kelompok". Ideologi dimaksudkan untuk mengatur masalah tindakan dan praktik individu atau anggota suatu kelompok yang bersifat umum dan abstrak, serta menjadikan nilai-nilai yang ada menjadi dasar bagaimana wacana bukan hanya sebagai barang yang alamiah, akan tetapi juga sebagai seperangkat gagasan atau kepercayaan yang dimiliki oleh golongan tertentu yang mempunyai tujuan sehingga menuntut orang yang meyakininya melakukan tindakan-tindakan tertentu.

Untuk dapat mengetahui ideologi pada sebuah novel, harus diketahui 
terlebih dahulu bagaimana stuktur struktur mikro yang terdapat dalam novel tersebut. struktur mikro ialah elemen-elemen pada sebuah novel seperti elemen sintaksis, elemen semantik, elemen leksikon dan elemen retoris. Untuk mengetahui bagaimana struktur mikro pada sebuah novel, maka diperlukan penganalisisan wacana secara kritis.

Analisis Wacana Kritis didefenisikan sebagai upaya untuk menjelaskan suatu teks pada fenemona sosial untuk mengetahui kepentingan yang termuat didalamnya. Wacana sebagai bentuk praktis sosial dapat dianalisis dengan Analisis Wacana Kritis untuk mengetahui hubungan antara wacana dan perkembangan sosial budaya pada domain sosial yang berbeda dalam dimensi linguistik (Eriyanto, 2006: 7).

Menurut van Dijk (1993) "Critical Discourse analysis is a type of discourse analysis research that primarily studies the way social power abuse, dominance, and inequality are enacted, reproduced, and resisted by text and talk in social and political contexts". Analisis Wacana Kritis digunakan untuk menganalisis wacana terhadap ilmu lain yang terdapat pada ranah politik, ras, gender, hegemoni, budaya, kelas sosial. Ranah kajian tersebut berpusat pada prinsip Analisis Wacana Kritis yakni: tindakan, konteks, historis, kekuasaan, dan ideologi.

Penelitian tentang ideologi pada novel Ayat-Ayat Cinta 2 ini dititikberatkan pada teori Analisis Wacana Kritis model van Dijk (1993). Adapun alasan peneliti menitikberatkan penelitian ini pada model van Dijk (1993) karena model ini melihat suatu teks terdiri atas beberapa struktur atau tingkatan yang saling mendukung, yakni stuktur makro, superstruktur dan struktur mikro yang dapat membongkar sebuah ideologi yang terkandung pada sebuah novel.

Berdasarkan paparan di atas, peneliti tertarik untuk menganalisis novel Ayat-Ayat Cinta 2 karya HES dengan pendekatan Analisis Wacana Kritis model van Dijk (1993).

\section{RUANG LINGKUP PENELITIAN}

Penelitian ini merupakan penelitian analisis isi yang membahas tentang tujuan atau ideologi HES menulis novel yang berjudul Ayat-Ayat Cinta 2 dengan pendekatan Analisis Wacana Kritis model van Dijk (1993). 


\section{TINJAUAN PUSTAKA}

Penelitian ini menggunakan teori Analisis Wacana Kritis Model Dijk (1993). Van Dijk (1993) mengimplikasikan bahwa wacana memiliki tiga dimensi: teks, kognisi sosial dan konteks. Dalam teks (stuktur mikro) van Dijk (1993) ideologi penulis novel Ayat-Ayat Cinta 2 dapat di temukan. Analisis Wacana Kritis van Dijk (1993) merupakan model yang paling banyak dijadikan kajian, karena mengelaborasi elemen-elemen wacana sehingga dapat didaya gunakan dan dipakai secara praktis (Eriyanto, 2006:221).

\section{METODE PENELITIAN}

Penelitian ini merupakan penelitian analisis isi, yaitu penelitian yang bersifat pembahasan mendalam terhadap isi suatu informasi tertulis. Paradigma yang digunakan dalam penelitian ini adalah paradigma kritis dengan menggunakan metode Analisis Wacana Kritis model van Dijk (1993). Data pada penelitian ini adalah kalimat dan paragraf yang mengandung ideologi yang terdapat pada novel Ayat-Ayat Cinta 2, sedangkan sumber data pada penelitian ini yaitu novel Ayat-Ayat Cinta 2 karya HES.

Teknik pengumpulan data dalam penelitian ini menggunakan teknik mencatat dokumen. Teknik mencatat dokumen dipilih karena sumber data dalam penelitian ini berupa dokumen tertulis yakni kalimat dan paragraf yang pada AyatAyat Cinta 2 karya HES. Selanjutnya data tersebut dideskripsikan atau dituliskan dalam bentuk tabel dengan mendaftar atau mengurutkan sesuai dengan urutan pengkodean data. Penulisan kode data sesuai dengan singkatan judul novel dan halaman novel. Pengkodean tersebut dilakukan untuk memudahkan peneliti dalam mengurutkan data. Setelah data terkumpul, maka peneliti menggunakan teknik analisis data Miles, Huberman dan Saldana (2014) yang menyatakan bahwa analisis data merupakan tahap selanjutnya setelah data terkumpul. Data yang sudah siap dan sudah dicatat dalam kartu data dan diklasifikasikan secara sistematis sesuai dengan kepentingan penelitian kemudian dianalisis. 


\section{PEMBAHASAN}

Data 1 AAC2/2 Suara khas bigpipe menggema dari Plaza Saint Giles Cathedral yang berdiri anggun menawan. Seorang lelaki tua berkumis pirang berpakaian tradisional Skotlandia tampak begitu khusyuk meniup alat musik bangsa Scots yang legendaris itu. Pakaian yang ia kenakan sangat khas memakai bawahan seperti rok yang disebut kilt berornamen tartan kotak-kotak merah hitam (Ayat-Ayat Cinta 2, Hal. 2)

Kata yang dicetak tebal pada data di atas merupakan pilihan kata yang dipakai oleh HES untuk menunjukkan ideologi yang terdapat pada kalimat tersebut, yaitu ideologi konservatif yang kelihatan dari kalimat yang menunjukkan usaha melestarikan budaya-budaya yang diwarisi oleh nenek moyang

Data 2 AAC2/3 La haula wa Ia quwwata illa billah, La haula wa la quwwata illa billah ... Lelaki itu bergumam mengulangulang zikirnya (Ayat-Ayat Cinta 2, Hal. 3)

Kata yang dicetak tebal pada data di atas merupakan pilihan kata yang dipakai oleh HES untuk menunjukkan ideologi Islam yang terdapat pada kalimat tersebut. Ideologi tersebut ditunjukkan melalui aktifitas zikir yang merupakan bagian dari kegiatan keagamaan umat Islam.

Data 3 AAC2/5 Satu hal yang harus kalian catat, hal pertama yang harus dimiliki seorang philologist adalah amanah. Saya diminta oleh Professor Charlotte untuk mengeluarkan dari kelas ini siapa saja yang belum membaca dua buku itu. Tanpa pandang bulu. Maka saya harus amanah. Tadi Juu Suh sudah saya keluarkan dari kelas. (Ayat-Ayat Cinta 2, Hal. 5)

Kata yang dicetak tebal pada data di atas merupakan pilihan kata yang dipakai oleh HES untuk menunjukkan ideologi Islam yang terdapat pada kalimat tersebut. Ideologi Islam tersebut ditunjukkan melalui kata yang amanah, yang mana dalam agama Islam amanah itu sangat penting. 
Data 4 AAC2/5 Maaf, bagi saya ini sudah tiba waktunya untuk ibadah. Apakah kalian terganggu jika saya shalat di sini? Jika kalian terganggu, saya akan shalat di office saya, lalu balik ke sini (Ayat-Ayat Cinta 2, Hal. 5)

Kata yang dicetak tebal pada data di atas merupakan pilihan kata yang dipakai oleh HES untuk menunjukkan ideologi yang terdapat pada kalimat tersebut yaitu kata ibadah dan shalat. Adapun ideologi yang terkandung pada kalimat tersebut di atas adalah ideologi Islam yang terdapat pada pilihan kata ibadah dan shalat. Kedua pilihan kata tersebut merupakan bentuk aktifitas umat Islam dalam menjalankan ibadahnya.

Data 5 AAC2/6 Fahri kemudian shalat dipojok ruangan itu menghadap kiblat. Sebagian mahasiswa terutama dua orang mahasiswa bule dan mahasiswi bermata sipit itu memerhatikan gerakan Fahri dengan saksama. (Ayat-Ayat Cinta 2, Hal. 6).

Kata yang dicetak tebal pada data di atas merupakan pilihan kata yang dipakai oleh HES untuk menunjukkan ideologi yang terdapat pada kalimat tersebut yaitu kata shalat dan Kiblat. Adapun ideologi yang terkandung pada kalimat tersebut di atas adalah ideologi Islam.

Data 6 AAC2/6-7 Dalam mengkaji manuskrip itu, saya harus menyelesaikan dan membaca tak kurang dari sepuluh kitab tafsir dari awal sampai akhir. Khatam dan tuntas Dan saya tidak menemukan Al-Qur'an memuat ajaran bom bunuh diri. Silakan ditulis, justru Al-Qur'an melarang membunuh dan Al-Qur'an justru menyuruh menjaga kehidupan. Membunuh satu orang sama saja membunuh seluruh umat manusia. Dan membiarkan hidup satu orang sama saja menghidupkan seluruh umat manusia. Kalau Al-Qur'an mengajarkan yang sedemikian baiknya, kenapa masih ada orang Islam yang melakukan bom bunuh diri? tanya Juu Suh (Ayat-Ayat Cinta 2, Hal. 6-7)

Kata yang dicetak tebal pada data di atas merupakan pilihan kata yang dipakai oleh HES untuk menunjukkan ideologi yang terdapat pada kalimat tersebut yaitu kata Al-Qur'an. Adapun ideologi yang terkandung pada kalimat tersebut di atas adalah ideologi Islam. 
Data 7 AAC2/8 Ia melakukan kajian tahqiq dan ta'liq secara ilmiah atas kumpulan wasiat $\mathrm{Al}$ =Allamah Habib Hasan bin Shaleh AlBahr berjudul Majmu' Washaya yang manuskripnya ia temukan di perpustakaan pribadi Habib Assegaf Solo, Indonesia. Sebelum masuk tahqiq dan ta'liq, ia meneliti sejarah bagaimana kumpulan wasiat itu sampai di Solo, lebih tepatnya ia mengurai jaringan ulama Yaman dalam berdakwah di Indonesia. Menghadaplah kepada Allah dengan hati luluh (Ayat-Ayat Cinta 2, Hal. 8 )

Kalimat yang dicetak tebal pada data di atas merupakan pilihan kalimat yang dipakai oleh HES untuk menunjukkan ideologi yang terdapat pada kalimat tersebut yaitu menghadaplah kepada Allah dengan hati luluh. Adapun ideologi yang terkandung pada kalimat tersebut di atas adalah ideologi Islam.

Data 8 AAC2/10 Fahri mengambil dua sajadah yang ia letakkan dalam laci paling bawah meja kerjanya. Mereka berdua lalu tengelam dalam kekhusyukan munajat kepada Allah saat hujan mengguyur Edinburgh dan lonceng dari St. Giles Cathedral berdentang-dentang (Ayat-Ayat Cinta 2, Hal. 10)

Kata dan kalimat yang dicetak tebal pada data di atas merupakan pilihan kata dan kalimat yang dipakai oleh HES untuk menunjukkan ideologi yang terdapat pada kalimat kekusyukan munajat kepada Allah dan kata sajadah. Adapun ideologi yang terkandung pada kalimat tersebut di atas adalah ideologi Islam.

Data 9 AAC2/12 Ia merasa, malaikat pun akan luluh jiwanya, bergetar hatinya, dan meneteskan air mata mendengar ayat itu dibaca oleh Maria (Ayat-Ayat Cinta 2, Hal. 12)

Kalimat yang dicetak tebal pada data di atas merupakan pilihan kalimat yang dipakai oleh HES untuk menunjukkan ideologi yang terdapat pada kalimat tersebut yaitu malaikat pun akan luluh jiwanya, bergetar hatinya, dan meneteskan air mata mendengar ayat itu dibaca oleh Maria. Adapun ideologi yang terkandung pada kalimat tersebut di atas adalah ideologi Islam.

Data 10 AAC2/13 Ia tidak tahu harus seperti apa mendoakan Aisha. Ia terus berdoa kepada Allah agar Allah terus mengasihi istrinya. dan terus menyelimutinya dengan selimut rahmat dan taufik (Ayat-Ayat Cinta 2, Hal. 13 ). 
Kalimat yang dicetak tebal pada data di atas merupakan pilihan kalimat yang dipakai oleh HES untuk menunjukkan ideologi. Adapun ideologi yang terkandung pada kalimat tersebut di atas adalah ideologi Islam.

Data 11 AAC2/14 Aisha begitu wangi parfumnya, membuat Fahri mabuk. Ya Allah, bagaimana mungkin aku bisa melupakannya. Ampuni hamba-Mu kalau sampai cintaku padanya menutupi cintaku kepada-Mu ya Allah! (Ayat-Ayat Cinta 2, Hal. 14)

Kalimat yang dicetak tebal pada data di atas merupakan pilihan kalimat yang dipakai oleh HES untuk menunjukkan ideologi yang terdapat pada kalimat tersebut. Adapun ideologi yang terkandung pada kalimat tersebut di atas adalah ideologi Islam.

Data 12 AAC2/18 Secara undang-undang negara tidak boleh diskriminasi. Tetetapi praktiknya tetap ada perlakuan diskriminasi bahkan intimidasi terhadap orang Islam, terutama setelah peristiwa 11 September 2001 dan bom London pada 7 Juli 2005. Cukuplah bahwa saya bisa menyampaikan akhlak Islam dan kualitas saya sebagai orang Islam (Ayat-Ayat Cinta 2, Hal. 18 )

Kalimat yang dicetak tebal pada data di atas merupakan pilihan kalimat yang dipakai oleh HES untuk menunjukkan ideologi yang terdapat pada kalimat tersebut. Adapun ideologi yang terkandung pada kalimat tersebut di atas adalah ideologi Islam.

Data 13 AAC2/20. Mintalah pertolongan Allah dalam setiap langkahmu, maju maupun mundur. Niscaya tidak akan sia-sia jerih payahmu dan akan tercapai cita-citamu. (Ayat-Ayat Cinta 2, Hal. 20 )

Kalimat yang dicetak tebal pada data di atas merupakan pilihan kalimat yang dipakai oleh HES untuk menunjukkan ideologi yang terdapat pada kalimat tersebut yaitu Mintalah pertolongan Allah, Adapun ideologi yang terkandung pada kalimat tersebut di atas adalah ideologi Islam

Data 14 AAC2/22 Fahri khawatir yang melakukan tindakan tidak bertanggung jawab itu ternyata adalah salah satu tetangganya yang akan membuat tetangganya itu 
semakin jauh darinya jika ia melibatkan organisasi formal atau lembaga hukum formal. (Ayat-Ayat Cinta 2, Hal. 22)

Kalimat yang dicetak tebal pada data di atas merupakan pilihan kalimat yang dipakai oleh HES untuk menunjukkan ideologi yang terdapat pada kalimat tersebut. Adapun ideologi yang terkandung pada kalimat tersebut di atas adalah ideologi Islam.

Data 15 AAC2/22 Kita sedikit ngebut supaya tidak terlambat jamaah gumam Fahri ketika sudah masuk mobil. Mobil itu bergerak meninggalkan garasi (Ayat-Ayat Cinta 2, Hal. 22 ).

Kalimat yang dicetak tebal pada data di atas merupakan pilihan kalimat yang dipakai oleh HES untuk menunjukkan ideologi yang terdapat pada kalimat tersebut yaitu supaya tidak terlambat jamaah, Adapun ideologi yang terkandung pada kalimat tersebut di atas adalah ideologi Islam.

Data 16 AAC2/23 Seringkali ia shalat Subuh lalu i'ftikaf sampai waktu Dhuha. Sepanjang i_tikaf itu ia gunakan untuk berdzikir dan muraj'aah hafalan Al-Qur'an-nya. (Ayat-Ayat Cinta 2, Hal. 23 )

Kata yang dicetak tebal pada data di atas merupakan pilihan kata yang dipakai oleh HES untuk menunjukkan ideologi yang terdapat pada kalimat tersebut yaitu Al-Qur'an dan berdzikir, Adapun ideologi yang terkandung pada kalimat tersebut di atas adalah ideologi Islam.

Data 17 AAC2/24 Jason melihat Fahri. Pandangan keduanya bertumbukan. Jason memasang muka tidak suka, bibirnya memberikan isyarat berbicara pada Fahri tanpa suara : FuckYou! Fahri kaget. Ia tetap membalas dengan senyum dan beristighfar didalam hati, Ia tidak mau meladen $i$ anak remaja berambut pirang itu. (Ayat-Ayat Cinta 2, Hal. 24 )

Kalimat yang dicetak tebal pada data di atas merupakan pilihan kalimat yang dipakai oleh HES untuk menunjukkan ideologi yang terdapat pada kalimat tersebut yaitu senyum dan beristighfar didalam hati, Adapun ideologi yang terkandung pada kalimat tersebut di atas adalah ideologi Islam. 
Data 18 AAC2/24 Tidak bisa, tuan. Susunan Al-Qur'an, susunan surat dan ayatnya itu sudah ditentukan oleh Allah. Allah melalui Malaikat Jibril menyampaikan kepada Nabi Muhammad, dengan susunan yang sudah ditetapkan. Nabi Muhammad menyampaikan kepada para sahabatnya. Para sahabatnya ribuan yang hafal AlQur'an menyampaikan kepadapara tabiin dan seterusnya hingga sampai kepada kita. (Ayat-Ayat Cinta 2, Hal. 24)

Kalimat yang dicetak tebal pada data di atas merupakan pilihan kalimat yang dipakai oleh HES untuk menunjukkan ideologi yang terdapat pada kalimat tersebut. Adapun ideologi yang terkandung pada kalimat tersebut di atas adalah ideologi Islam.

Data 19 AAC2/38 Dalam kitab Fathul Bari. Ibnu Hajar, menulis bahwa Abu Umamah dan Ibnu Uyainah juga melakukan hal tersebut, artinya mengucapkan salam kepada orang yang bukan Muslim. Di situ dijelaskan, bila Abu Umamah pulang ke rumahnya, ia selalu mengucapkan salam kepada orang orang yang dilaluinya, baik itu orang Islam, Kristen, anak kecil, maupun orang tua. Ketika ia ditanya mengenai hal itu, ia menjawab, Kita diperintahkan untuk menyebarkan salam. (Ayat-Ayat Cinta 2, Hal. 38).

Kalimat yang dicetak tebal pada data di atas merupakan pilihan kalimat yang dipakai oleh HES untuk menunjukkan ideologi yang terdapat pada kalimat tersebut. Adapun ideologi yang terkandung pada kalimat tersebut di atas adalah ideologi Islam.

Data 20 AAC2/39-40 Ibrahim An-Nakhai mangatakan, Hadist Abu Hurairah; janganlah kalian memulai mengucapkan salam kepada mereka, itu jika kalian tidak memiliki alasan untuk memulai mengucapkan salam kepada mereka. Baik itu memenuhi penghormatan, hak tetangga atau bepergian. 'Artinya jika ada hak kekerabatan, persahabatan, tetangga, bepergian dan keperluan, maka boleh mendahului mengucapkansalam. Apalagi jika salamnya bukan assalamualaikum, misalnya good morning, hai, hello, maka tidak ada masalah sama sekali. (Ayat-Ayat Cinta 2, Hal. 39-40) 
Kalimat yang dicetak tebal pada data di atas merupakan pilihan kalimat yang dipakai oleh HES untuk menunjukkan ideologi yang terdapat pada kalimat tersebut yaitu mengucapkan salam kepada orang yang bukan Muslim dan Kita diperintahkan untuk menyebarkan salam. Adapun ideologi yang terkandung pada kalimat tersebut di atas adalah ideologi Islam.

Data 21 AAC2/40 Ya Allah. bagaimana mungkin aku bisa melupakannya. Ampuni hamba-Mu kalau sampai cintaku padanya menutupi cintaku kepada-Mu, ya Allah! lirih Fahri sambil menyeka air matanya. (Ayat-Ayat Cinta 2, Hal. 40)

Frasa yang dicetak tebal pada data di atas merupakan pilihan Frasa kalimat yang dipakai oleh HES untuk menunjukkan ideologi yang terdapat pada kalimat tersebut yaitu frasa $\mathbf{Y a}$ Allah dan frasa Ampuni hamba-Mu Adapun ideologi yang terkandung pada kalimat tersebut di atas adalah ideologi Islam.

Menurut HES melalui novelnya yang dikenal bernuansa Islam, ajaran Islam tidak hanya mengatur hubungan manusia dengan Allah, tetapi juga mengatur hubungan dengan sesama manusia, seperti ajaran untuk memuliakan sesama manusia, menghormati orang yang lebih tua, menghormati istri, menghormati tamu, dan menjaga pergaulan dengan lawan jenis. Dalam novelnovel karyanya juga HES mengajak agar semua umat Islam dapat memuliakan sesama manusia, baik muslim maupun non muslim.

Menurut HES, seorang muslim harus menghormati sesama manusia. Seorang muslim juga diperintahkan untuk berkata yang baik terhadap sesama manusia dan menghindari kata-kata yang kotor dan hal tersebut sesuai dengan surat Al-Baqarah 83 disebutkan "Hendaklah kamu berkata terhadap manusia dengan perkataan yang baik-baik". Ajaran itu dapat dilihat ketika salah satu tokoh utama dalam memberikan tempat duduknya didalam bus kepada seorang penumpang turis dari Amerika. Orang-orang di dalam bus memprotes tindakan tokoh utama tersebut karena orang Amerika dianggap sebagai musuh orang muslim. Kemudian HES melalui tokoh utama tersebut mengingatkan saudarasaudaranya sesama muslim bahwa agama Islam melarang pemeluknya untuk mengumpat dan mengeluarkan kata-kata kotor 
Kemudian, HES juga mengajarkan bahwa sebagai seorang muslim, harus mengajarkan umatnya untuk mencintai dan menghormati sesama manusia meskipun berbeda agama, suku, dan golongannya.

Dalam novelnya juga HES mengajak agar semua pembaca dapat menghormati orang yang lebih tua dan menyayangi yang lebih muda karena hal tersebut merupakan anjuran Rasulullah. Selain itu dalam novelnya HES juga mengajak pembaca untuk menghormati perempuan karena dalam Alquran memang ada sebuah ayat yang mengharuskan laki-laki bersikap mendidik, dan membimbing seorang istri yang tidaklagi menghormati, mencintai, menjaga, dan memuliakan suaminya.

\section{KESIMPULAN}

Paparan data di atas menyimpulkan bahwa adapun bentuk ideologi yang terealisasi pada level struktur mikro adalah ideologi Islam, ideologi konservatif dan ideologi nasionalisme dan ideologi tersebut di sajikan melalui pilihan-pilihan kata seperti, frasa dan kalimat.

\section{DAFTAR PUSTAKA}

Dijk, Teun A.Van. Ed (1985). Handbook of Discourse Analisis: Discourse Analisys in society. London. Academic Press, Inc.

Eriyanto. (2006). Pengantar Analisis Wacana. Pengantar Analisis Teks Media. Yogyakarta: Lkis

Kusmayadi, Ismail. (2008). “Think Smart Bahasa Indonesia”. Bandung: Grafindo Media Pratama

Miles, Metthew B, A. Michael Huberman and Johnny Saldana. (2014). Qualitative Data Analysis, A Methods Sourcebook, Third Edition. Sage Publications, Inc.

Sugihastuti, Suharto. (2002). Kritik Sastra Feminis, Teori dan Aplikasinya. Yogyakarta: Pustaka Pelajar. 